\title{
PROJECT ACTIVITIES OF BACHELOR STUDENTS OF A PEDAGOGICAL UNIVERSITY AS A CONDITION FOR PREPARING SCHOOLCHILDREN'S RESEARCH ACTIVITIES
}

(C) 2019

\author{
Zaitseva Olga Arkadyevna, postgraduate student \\ of Ecological Education and Rational Environmental Management Department; teacher of Biology \\ Minin Nizhny Novgorod State Pedagogical University (Nizhny Novgorod, Russian Federation); \\ Secondary School № 151 (Nizhny Novgorod, Russian Federation)
}

Abstract. The paper discusses current issues of training a professional teacher, a successful organizer of schoolchildren's research activities. The material is presented in terms of new standards. The author discusses innovative forms of educational process organization at university and school - the creation of a single educational space based on the principles of science and education integration. The main condition for schoolchildren's research potential development and successful teachers' development is the project activity of students and schoolchildren in the framework of cooperation. A structural model of network interaction between the Minin Nizhny Novgorod State Pedagogical University, schools № 151, 129, 173 of Nizhny Novgorod, the Immanuel Kant Baltic Federal University (Kaliningrad) and the A.N. Severtsov Institute of Ecology and Evolution of the Russian Academy of Sciences (Moscow) has been developed. This model is a key factor contributing to the solution of the problem of high-quality training of a prospective teacher majoring in Biology who will be able to organize students' research activities and develop their creative activity. The experience of the development and testing of various joint scientific, social and creative projects is shown. The data of the experiment are presented, which speak about the success of the events held as part of the implementation of the project technology.

Keywords: research potential; schoolchildren's research activities; project activities; research creativity; professional competencies; professional adaptation; network interaction; integration of science and education; student tutoring; clinical practice.

\section{НРАВСТВЕННЫЕ ЦЕННОСТИ В КОНТЕКСТЕ ФИЗИЧЕСКОГО ВОСПИТАНИЯ КУРСАНТОВ - БУДУЩИХ СОТРУДНИКОВ УГОЛОВНО-ИСПОЛНИТЕЛЬНОЙ СИСТЕМЫ}

(C) 2019

Клычков Сергей Александрович, преподаватель кафедры физической и тактико-специальной подготовки Самарский юридический институт ФСИН России (2. Самара, Российская Федераџия)

Аннотащия. В статье обосновывается актуальность проблемы оптимального соотношения физической подготовки и нравственного воспитания в образовательном процессе вуза, осуществляющего подготовку сотрудников уголовно-исполнительной системы (УИС). В качестве одного из путей решения данной проблемы предлагается приобщение курсантов - будущих сотрудников УИС к нравственным ценностям в процессе физического воспитания. Обосновывается, что нравственные ценности - это ценности, социально одобряемые и разделяемые большинством людей, что они связаны с нравственностью как с этической категорией и ее структурой. Представляются классические признаки нравственных ценностей (ответственность человека за эти ценности; осознание нравственной несостоятельности, затрагивающей совесть; необходимость таких ценностей; отношение нравственных ценностей к награде и наказанию) и их классификация (фундаментальные, базисные и системные общественные духовно-нравственные ценности). Осуществляется отбор нравственных ценностей, к которым необходимо приобщать курсантов - будущих сотрудников УИС в процессе физического воспитания («добро», «долг», «взаимопонимание», «милосердие», «ответственность», «правда», «свобода», «совесть», «справедливость», «эмпатия»). Доказывается, что ценность «альтруизм», являясь ценностью, к которой необходимо приобщать курсантов, конкретизируется ценностями «милосердие» и «справедливость» и поэтому не представлена в общем списке ценностей. Справедливость и милосердие рассматриваются как стороны золотого правила нравственности, двустороннее действие которого способствует возникновению эффектов со-чувствия, со-действия, со-помощи, со-участия. Представляется характеристика ценностей «добро», «взаимопонимание», «свобода», «ответственность», «правда», «эмпатия» как ценностей, к которым необходимо приобщать курсанта в процессе физического воспитания для развития его как нравственной личности.

Ключевые слова: курсант - будущий сотрудник уголовно-исполнительной системы; нравственность; ценность; нравственные ценности; воспитание; физическое воспитание; добро; взаимопонимание; свобода; ответственность; справедливость; милосердие; совесть; эмпатия; золотое правило нравственности.

В процессе профессиональной подготовки курсантов - будущих сотрудников уголовно-исполнительной системы (УИС) особое внимание уделяется занятиям по физической культуре, включающим систему специальных упражнений, направленных на Самарский научный вестник. 2019. Т. 8, № 3 (28) развитие физических и духовных сил курсантов. При этом развиваются сила, ловкость, выносливость, двигательные реакции - иными словами, те физические качества, которые необходимы сотруднику УИС, так как его профессиональная деятельность связана с 
осуществлением охраны спецконтингента, с обеспечением безопасности при конвоировании, а в особых ситуациях - с задержанием и преследованием правонарушителей.

Хорошая физическая подготовка сотрудника УИС, несомненно, важна, так как от ее уровня зачастую зависит жизнь и здоровье как самого сотрудника, так и других людей. В то же время профессиональная деятельность в УИС связана с тем, что сотрудник априори обладает властью над осужденными, которые обязаны подчиняться его требованиям. И здесь высвечивается уже нравственная проблема - проблема отношения человека, обладающего властью, к человеку подвластному. Естественно, что осужденный за нарушение закона человек, особенно совершивший тяжкие преступления, не вызывает сочувствия. Однако, если сегодня сотрудник УИС использует в своей профессиональной деятельности физическую силу неадекватно конкретной ситуации, а лишь, допустим, чтобы показать свою власть над осужденным, то завтра он может употребить силу и против другого человека (соседа, участника дорожного движения и т.д.), руководствуясь принципом: сильный всегда прав. Чтобы такого не произошло, необходимо в процессе физического воспитания в вузе приобщать курсантов - будущих сотрудников УИС к нравственным ценностям, которые становятся мотивами их поведения в ситуациях, требующих использования физических качеств. Для формирования личности курсанта, у которого телесность и нравственность находятся в гармонии, необходимо использовать возможности физического воспитания, которое, наряду с осуществлением физического развития личности, призвано, как пишет И.Ф. Харламов, возбуждать потребность в занятиях физкультурой и спортом, «способствовать глубокому осмыслению психофизиологических основ физического развития и укрепления здоровья, а также создавать условия для повышения влияния последних на умственное, нравственное и эстетическое воспитание» [1, с. 385].

В рамках данной статьи мы остановимся на нравственных ценностях, приобщение к которым курсантов - будущих сотрудников УИС может осуществляться в контексте физического воспитания.

Мир ценностей богат и разнообразен. В научной литературе представлены различные основания, по которым классифицируются ценности. Так, М.С. Каган выделяет в аксиосфере культуры эстетические, нравственные, политические, художественные, религиозные, экзистенциальные ценности [2, с. 88]. Подробный анализ видов ценностей представлен в работе К.С. Талановой, которая пишет о семейных, профессиональных, моральных, эстетических, религиозных, научных, экономических, политических, национальных и иных ценностях [3, с. 194].

Как видим, нравственные (моральные) ценности являются одним из видов ценностей. Мы полагаем, что это ценности социально одобряемые, которые разделяются большинством людей.

Нравственные ценности связаны с нравственностью как с этической категорией и ее структурой. T.С. Лапина, рассматривая структуру индивидуальной нравственности человека, выделяет нравственные представления о норме, о добродетели и о пороке, о добре и зле, о нормах поведения, о справедли- вости и др.; а также нравственные убеждения; нравственные взгляды; нравственные чувства; нравственные качества, которые (качества) становятся подлинно реальными в том случае, если они проявляются в поведении человека [4, с. 119-123].

На первый взгляд, в предлагаемой ученым структуре индивидуальной нравственности отсутствуют ценности. Однако, несмотря на отсутствие прямого указания на ценности как на элементы нравственности, они все-таки присутствуют в структуре человеческой нравственности. Добро, справедливость, долг, ответственность, о которых пишет Т.С. Лапина, - все это нравственные ценности. Как утверждает А.Г. Харчев, «это не какая-то особая область морали, а сама мораль и отдельные ее элементы, взятые в их социальных значениях и ролях, соотнесенные с потребностями общества и личности» [5, с. 76].

Какие же ценности могут быть отнесены к нравственным?

Классические признаки нравственных ценностей представлены в трудах Д. Гильдебранда, который в качестве признаков нравственных ценностей, отличающих их от других ценностей, предлагает следующие: «ответственность человека за эти ценности; осознание нравственной несостоятельности, затрагивающей совесть; необходимость таких ценностей; отношение нравственных ценностей к награде и наказанию» [6, с. 216-223]. Но конкретный перечень ценностей Д. Гильдебранд не представляет.

Обращение к современной научной литературе показало, что классификации нравственных ценностей широко представлены в работе Е.А. Савченко, Э.М. Молчан «Духовно-нравственные ценности: аксиологические классификации» [7]. Анализ научной литературы, проведенный учеными, позволил им определить систему духовно-нравственных ценностей, образуемую 1) фундаментальными, 2) базисными и 3) системными общественными духовно-нравственными ценностями. К первым относятся системные и предметные духовно-нравственные ценности; ко вторым - неживая и живая природа; к третьим - экономика, политика, право, гражданское общество, духовная сфера [7, с. 23].

Нас, конечно же, в первую очередь интересуют конкретные нравственные ценности, к которым необходимо приобщать курсантов в процессе физического воспитания.

Анализ научной литературы, затрагивающей проблему нравственных ценностей, показал, что к нравственным ученые относят разные ценности. Это благо, добро, справедливость, милосердие, честь, долг и т.д. Нам необходимо выбрать среди них те, приобщение к которым курсантов в процессе физического воспитания даст возможность воспитывать нравственную личность будущего сотрудника УИС.

Проблема состоит в том, что в нашей работе речь идет не о формировании нравственности в целом, а о формировании личности курсанта, у которого телесно-физическое и нравственное развитие находятся в гармоническом единстве. В.А. Баранов утверждает: «Физическая культура может быть представлена как институт качества жизни и выполнять функции воспроизводства целостности человека и многомерной личности в современном российском социуме, если будет .. <..> .. нивелировано противопоставление 
"человека телесного" и "человека духовного", что позволит преодолеть сложившийся и явно прогрессирующий в последнее время "телесный негативизм" как проявление, с одной стороны, равнодушия к собственному здоровью, "познанию тела", а с другой стороны - излишнего возвеличивания внешних атрибутов телесности» [8, с. 75].

Итак, обратимся к представлениям ученых о конкретных нравственных ценностях и отберем те, к которым, с нашей точки зрения, необходимо будем приобщать курсантов.

Обширный список нравственных ценностей предлагается О.Т. Богомоловым и В.М. Кривошеевым. На первое место среди нравственных ценностей ученые ставят доверие, затем говорят о чести и человеческом достоинстве, неприятии всякой лжи и лицемерия, сочувствии и сострадании к страждущим, добросовестности и обязательности [9, с. 63]. С точки зрения А.Р. Ерошенко, нравственные ценности выступают в роли универсальных ценностей, среди которых «истина, добро, любовь, милосердие, красота, вера, свобода, правда, справедливость» [10, с. 87-88]. И.А. Соловцова отмечает, что «в качестве интенции позитивного духовного становления человека исследователи, как правило, называют абсолютные ценности. К ним традиционно относят триаду "Истина Добро - Красота"» [11, с. 115].

Особый интерес представляют для нас работы И.Б. Акимова и С.В. Скрыгина, которые рассматривают нравственные ценности с позиции приобщения к ним учащихся в процессе физического воспитания. Так, И.Б. Акимов предлагает следующие ценности: «добро», «долг», «достоинство», «милосердие», «ответственность», «свобода», «совесть», «справедливость», «честность», «честь» [12, с. 9]. С.В. Скрыгин утверждает, что на занятиях физической культурой надо воспитывать такие ценности, как жизнь, счастье, свобода, правда, мир, добро, нравственное здоровье [13].

Заметим, что И.Б. Акимов ведет речь об учащихся специализированного учебного заведения, в котором обучаются будущие или уже действующие профессиональных спортсмены [12], а С.В. Скрыгин - о школьниках. В нашей работе мы говорим о приобщении к нравственным ценностям в процессе физического воспитания курсантов - будущих сотрудников УИС. Однако полагаем, что идеи И.Б. Акимова и С.В. Скрыгина относительно нравственных ценностей, приобщение к которым возможно в процессе физического воспитания, могут быть экстраполированы в контексте физического воспитания курсантов.

Среди ценностей, предлагаемых И.Б. Акимовым и С.В. Скрыгиным, все ценности могут быть рассмотрены как нравственные, за исключением нравственного здоровья, которое является видом здоровья человека наряду со здоровьем физическим и психическим. Г.Ю. Беляев и А.В. Беляева утверждают: «В педагогической практике целесообразно говорить о трех видах здоровья: здоровье физическом, психическом и нравственном (социальном). Нравственное здоровье определяется теми моральными принципами, которые являются основой социальной жизни человека, т.е. жизни в человеческом обществе. Признаками нравственного здоровья человека являются, прежде всего, сознательное отношение к труду, овладение сокровищами культуры, активное неприятие нравов и привычек, противоречащих нормальному образу жизни. Физически и психически здоровый человек может быть нравственным уродом, если он пренебрегает нормами морали. Поэтому нравственное здоровье считается высшей мерой человеческого здоровья. ... <..> ... Нравственно здоровым людям присущ ряд общечеловеческих качеств, которые и делают их настоящими, социально ответственными гражданами» [14, с. 174-175].

Выявляя систему ценностей, к которым необходимо приобщать курсантов в процессе физического воспитания, мы пришли к убеждению, что среди таких ценностей должны находиться нравственные ценности, связанные с добродетельностью человека, как направленностью личности «на совершение этически ценных поступков, честное выполнение своего долга» $[15$, с. 60] а также ценности, обеспечивающие его жизнедеятельность.

Добродетели связаны с позитивными образцами поведения человека, соотносимы с нравственным идеалом. Добродетели по своей природе социальны, но по формам выражения индивидуальны. Жизнедеятельность человека включает его социальное поведение и творческую активность, она связана с социально-значимой самореализацией личности. Ценности, обеспечивающие жизнедеятельность человека, включая эталоны должного (нравственного), задают основания жизненно важным формам поведения и деятельности - нравственным формам. Данным требованиям, с нашей точки зрения, отвечают ценности, выделенные Н.Б. Крыловой. Это ценности-добродетели (альтруизм, другодоминантность, встреча, терпимость, эмпатия) и ценности жизнедеятельности (самореализация, свобода, интерес, взаимопонимание, сотрудничество, поддержка) [16, с. 43].

Итак, анализ научной литературы, посвященной проблеме нравственных ценностей, позволил нам остановиться на ценностях, предложенных И.Б. Акимовым, С.В. Скрыгиным и Н.Б. Крыловой. Мы отобрали среди представленных ценностей такие ценности, как «добро», «долг», «взаимопонимание», «милосердие», «ответственность», «правда», «свобода», «совесть», «справедливость», «эмпатия».

Заметим, что ценность «альтруизм» как ценностьдобродетель также выбрана нами, так как, по утверждению Ю.А. Шрейдера, превращение утилитарных благ в моральные ценности осуществляется посредством альтруизма [17, с. 39]. Именно альтруистическая направленность поступка характеризует его как нравственный.

Альтруизм конкретизирует милосердие и справедливость, проявляемые одним человеком по отношению к другому, поэтому можно утверждать, что ценность «альтруизм» представлена ценностями «милосердие» и «справедливость». Такая представленность основывается на положении В.С. Соловьева о принципе альтруизма. Данный принцип разбивается им на правило справедливости (отрицательное): «Не делай другому ничего такого, чего себе не хочешь от других» и правило милосердия (положительное): «Делай другому все то, чего сам хотел бы от других» [18, с. 111-112]. Правило справедливости и правило милосердия представляют собой вариации золотого правила нравственности. «"Прожи- 
вание" человека в поле золотого правила нравственности, - пишут О.К. Позднякова и В.С. Поздняков, расширяет его коммуникативный горизонт. Данное правило направлено не просто на ограничение зла (в отрицательной формулировке) и утверждение добра (в положительной формулировке) < ..> имеет целью минимум зла и максимум добра» [19, с. 908]. Двустороннее действие золотого правила нравственности способствует возникновению таких эффектов, как со-чувствие, со-действие, со-помощь, со-участие.

Ж. Лакруа следующим образом обосновывает единство милосердия и справедливости: «Милосердие без справедливости - все равно, что мысль без языка, интуиция без рассуждения... <..> Справедливость без милосердия - это язык без мысли, рассуждение без интуиции, в конечном итоге - небытие. $<\ldots>$... любая справедливость, стремящаяся отделиться от милосердия и замкнуться в себе, разрушительна по отношению к своей природе. ... < ..> .. Милосердие - это движущая сила справедливости» [20, c. 183-184].

Сущность справедливости как мерной характеристики человеческих отношений четко выражает Н. Гартман: «Не все для меня, но мне и другому одно и то же» [21, с. 402]. Данное понимание справедливости связано с равенством людей. В рамках нашей работы это означает, что курсанты равны в нравственном отношении, что они не должны кичиться перед другими людьми своим превосходством, например, в физическом развитии, в служебном положении и т.д.

Обратимся к некоторым другим ценностям.

Ценность «добро», по мнению А.А. Гусейнова и Р.Г. Апресяна, предполагает установление взаимопонимания и согласия между людьми и проявляется в милосердии и любви [22, с. 247]. Именно добро дает возможность как отдельному человеку, так и обществу в целом успешно развиваться, совершенствоваться, достигать гармонии. Приобщение курсантов к добру как к ценности позволяет, развивая их физические силы, ориентировать будущих сотрудников УИС на использование этих сил для установления нравственных отношений с другими людьми.

Ценность «взаимопонимание» предполагает, по утверждению А.И. Титаренко, «согласование неодинаковых норм, запретов, ориентаций различных общающихся субъектов, умение найти более общую систему моральных ценностей, через которую, как через однопорядковую систему координат, их можно согласовать» [23, с. 156].

Ценность «свобода» подразумевает ценность «ответственность». Не случайно данные ценности в научной литературе рассматриваются во взаимосвязи. Е.В. Золотухина-Аболина пишет: «Ответственность - оборотная сторона свободы, ee "alter ego" второе "я". Ответственность неразрывно связана со свободой и всегда сопровождает ее. Тот, кто действует свободно, полностью отвечает за содеянное им» [24, с. 223]. Прямую зависимость свободы и ответственности отмечает и Т.В. Мишаткина: чем шире свобода, тем больше ответственность [25, с. 148].

Ценность «правда» реализуется в правдивости действий и поступков, верность которым распространяется на умонастроение и является основой доверия между людьми. С точки зрения Н. Гартмана, подчеркивающего нравственную ценность правдивости, правдивость означает, что человек достоин доверия. При этом вместе с правдивостью речи существует правдивость действий и поступков [21, с. 432435]. Именно правда находится в основаниях доверия между людьми, содержательное ядро которого образует достоинство другого человека. Доверие, основанное на достоинстве, становится ценностным условием взаимопонимания, согласия между людьми.

Ценность «совесть» связана со способностью человека, критически оценивая свои поступки, мысли, желания, осознавать и переживать свое несоответствие должному как собственное несовершенство [26, с. 449]. Ю.А. Шрейдер рассматривает совесть как моральный компас [21, с. 185]. Присутствие в ценностной сфере сознания курсантов ценности «совесть» создает условия для актуализации полученной ими нравственно значимой информацию и для реализации ее в своем поведении.

Ценность «эмпатия», по утверждению Н.Б. Крыловой, базируется на культурном механизме принятия [16, с. 49]. Как подчеркивал К. Роджерс, эмпатия предполагает способность посмотреть на мир глазами другого человека, «проникнуть во внутренний мир человека, чтобы сопровождать его в путешествие к истокам самого себя» [27, с. 106]. Переживание и сочувствие представляют собой высшие формы эмпатии, так как именно в них выражается отношение человека к другим людям. Сочувствие означает понимание мыслей и чувств другого человека, переживание того, что переживает другой. Сочувствие дает возможность, поставив себя на место другого человека, увидеть в нем себе подобного. Чуткость, доброжелательность, отзывчивость, непримиримость к равнодушию и жестокости - это и есть реализация эмпатии как нравственной ценности. Нравственное взаимодействие людей возможно в том случае, если будет преодолен эгоцентризм и сделана попытка встать на позицию другого человека и, соответственно, попытаться эту позицию понять. Понимание позиции другого человека дает возможность найти ее сильные и слабые стороны. Важно, что поиск таких сторон должен осуществляться по критерию добра.

Итак, если развитие физических качеств курсанта осуществляется в процессе физической подготовки, то формирование его нравственных качеств, развитие его нравственности возможно через приобщение курсанта - будущего сотрудника ФСИН к нравственным ценностям. Такое приобщение, реализуемое в процессе физического воспитания, способствует формированию личности курсанта, который использует свои физические силы и возможности, руководствуясь нравственными критериями. Подчеркнем еще раз, что развитие нравственности предполагает и реализацию ценностей. Имеется в виду не процессуальный, а нравственный аспект такой реализации. Важно, чтобы те нравственные ценности, к которым преподаватель приобщает курсантов, составляли основу ценностных ориентаций самого преподавателя. В приобщении курсантов к нравственным ценностям в процессе физического воспитания важным является реализация преподавателем собственных нравственных ценностей таких образом, чтобы они становились ценностями для курсанта. 


\section{Список литературы:}

1. Харламов И.Ф. Педагогика. Минск: БГУ, 1979. $464 \mathrm{c}$.

2. Каган М.С. Философская теория ценности. СПб.: Петрополис, 1997. 205 с.

3. Таланова К.С. Ценностное ядро духовно-нравственного кризиса: дефиниции, типологии, система ценностей // Вестник МГУ. Серия 18: Социология и политология. 2014. № 3. С. 179-200.

4. Лапина Т.С. Проблема индивидуальной нравственности // Мораль и этическая теория. М.: Наука, 1974. C. 106-143.

5. Харчев А.Г. Этика и мораль // Предмет и система этики. М.: Институт философии АН СССР; София: Институт философии БАН: 1973. С. 69-91.

6. Гильдебранд Д. Этика. СПб.: Алетейя, 2001. $570 \mathrm{c}$.

7. Савченко Е.А., Молчан Э.М. Духовно-нравственные ценности: аксиологические классификации // Педагогическое образование и наука. 2013. № 6. C. 20-27.

8. Баранов В.А. Физическая культура как категория ценности и качества бытия // Вопросы культурологии. 2010. № 11. С. 72-76.

9. Богомолов О.Т., Кривошеев В.М. Мораль, нравственность, этика - три источника нравственного возрождения России // Экономические стратегии. 2013. № 8. С. 63-67.

10. Ерошенко А.Р. Фразеологическая концептуализация понятия «нравственность»: религиозно-православный аспект // Лингвориторическая парадигма: теоретические и прикладные аспекты. 2009. № 13. С. 87-92.

11. Соловцова И.А. Духовность и нравственность как основополагающие категории духовного воспитания // Известия Волгоградского государственного педагогического университета. 2006. № 1. С. 113116.

12. Акимов И.Б. Содержание и методы приобщения учащихся к нравственным ценностям в процессе физического воспитания: автореф. дис. ... канд. пед. наук: 13.00.01. Самара, 2015. 26 с.

13. Скрыгин С.В. Нравственные ценности для воспитания учеников на уроках физической культуры // Электронный научный журнал. 2017. № 42 (19). C. 351-354.

14. Беляев Г.Ю., Беляева А.В. Воспитание будущего учителя в междисциплинарном контексте // Вопросы воспитания. 2012. № 2 (11). С. 173-179.

15. Полонский В.М.Большой тематический словарь по образованию и педагогике. М.: Народное образование, $2017.840 \mathrm{c}$.

16. Крылова Н.Б. Культурология образования. М.: Народное образование, 2000. 272 с.

17. Шрейдер Ю.А. Этика. М.: Текст, 1998. 271 с.

18. Соловьев В.С. Оправдание добра: нравственная философия. М.: Республика, 1996. 479 с.

19. Позднякова О.К., Поздняков В.С. Золотое правило нравственности в моральном выборе учителя // Известия Самарского научного центра Российской академии наук. 2013. Т. 15, № 2 (4). С. 907-913.

20. Лакруа Ж. Справедливость и милосердие // Культурология. 2003. № 1 (24). С. 176-192.

21. Гартман Н. Этика. СПб.: Владимир Даль, 2002. $707 \mathrm{c}$.

22. Гусейнов А.А., Апресян Р.Г. Этика: учебник. М.: Гардарики, 1998. 472 с.

23. Титаренко А.И. Антиидеи. Опыт социальноэтического анализа. М.: Политиздат, 1976. 399 с.

24. Золотухина-Аболина Е.В. Современная этика. М.: ИКЦ «МарТ», Ростов-на-Дону: Издательский центр «МарТ», 2003. 416 с.

25. Мишаткина Т.В. Свобода и ответственность // Этика / под ред. Т.В. Мишаткиной, Я.С. Яскевича. Минск: Новое знание, 2002. С. 138-152.

26. Этика: энциклопедический словарь / под ред. Р.Г. Аперсяна, А.А. Гусейнова. М.: Гардарики, 2001. $671 \mathrm{c}$.

27. Роджерс К. Взгляд на психотерапию. Становление человека. М.: Прогресс, 1994. 480 с.

\section{MORAL VALUES IN THE CONTEXT OF PHYSICAL EDUCATION OF STUDENTS - PROSPECTIVE EMPLOYEES OF THE PENITENTIARY SYSTEM}

(C) 2019

Klychkov Sergey Aleksandrovich, lecturer of Physical and Special Tactical Training Department
Samara Law Institute of the Federal Penitentiary Service of Russia (Samara, Russian Federation)

Abstract. The paper deals with the optimal ratio of physical training and moral education in the educational process of a higher education institution that trains employees of the penitentiary system (PS). As one of the ways to solve this problem, it is proposed to introduce moral values to students - prospective employees of the PS in the process of physical education. It is substantiated that moral values are values that are socially approved and shared by most people, they are associated with morality as an ethical category and its structure. There are classic signs of moral values (responsibility of a person for these values; awareness of moral insolvency affecting the conscience; the need for such values; the ratio of moral values to reward and punishment) and their classification (fundamental, basic and systemic social and moral values). The author has selected moral values that should be introduced to cadets prospective employees of the PS in the process of physical education («good», «duty», «mutual understanding», «mercy», «responsibility», «truth», «freedom», «conscience», «justice», «empathy»). It is proved that the value «altruism» is concretized by the values «charity» and «justice» and therefore is not represented in the general list of values. Justice and mercy are considered to be sides of the golden rule of morality, the bilateral action of which contributes to co-feeling, co-action, co-help, co-participation. Values «good», «mutual understanding», «freedom», «responsibility», «truth» and «empathy» are described as values that should be introduced to a cadet in the process of physical education in order to develop him as a moral personality.

Keywords: cadet - prospective employee of penitentiary system; morality; value; moral values; education; physical education; kindness; mutual understanding; freedom; responsibility; justice; mercy; conscience; empathy; golden rule of morality. 